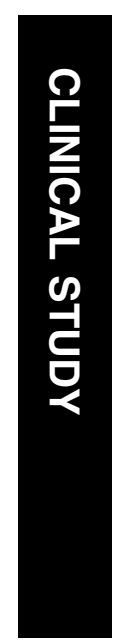

\section{Astigmatism outcomes of scleral tunnel and clear corneal incisions for congenital cataract surgery}

SM Bar-Sela ${ }^{1,2}$ and A Spierer ${ }^{1,2}$
Keywords: astigmatism; congenital cataract; surgery

\section{Introduction}

Corneal astigmatism after cataract surgery is a well-documented finding in adults. The amount of astigmatism depends on various factors, such as the type and location of the surgical incision, the amount of scleral cauterization performed, the suturing material used, suture placement, and postoperative use of steroids. ${ }^{1-3}$

In adults, only mild spontaneous changes in the amount of postoperative astigmatism have been described. ${ }^{4,5}$ An effective way to reduce or eliminate the postoperative astigmatism is through the removal of one or more interrupted or continuous sutures. ${ }^{6-9}$ This procedure relieves wound compression, thereby altering the corneal curvature. Suture removal is recommended only in eyes with postoperative astigmatism of at least 3 Diopter (D). ${ }^{7,10}$

Recent reports have documented the finding of spontaneous regression in astigmatism after cataract surgery in children. ${ }^{11,12} \mathrm{We}$

demonstrated the sequel of a specific group of children in whom astigmatism of at least $3 \mathrm{D}$ was recorded 1 week after congenital cataract operation. ${ }^{11}$ In this study, we reviewed the refractive astigmatism outcomes of all the children who underwent congenital cataract operation in our department using clear corneal or scleral tunnel incisions.

\section{Materials and methods}

We reviewed the medical records of 46 children (67 eyes), who underwent surgery for congenital cataract between 1996 and 2001, and 
did not have suture removal during the 5-month followup period. All included patients appeared for their scheduled follow-up examinations, and were included in the study. There were no other ocular or systemic abnormalities in the study population.

All patients had undergone extracapsular cataract extraction and intraocular lens (IOL) implantation. The IOL power was chosen for targeted refraction to match the eye's expected refractive growth with age. Two types of surgical incisions were used. The following procedure was common to all techniques. Two paracentesis ports were opened at the limbus at the 2- and 10-o'clock positions. An anterior chamber maintainer (Visitec; Warwickshire, England, UK) was used, and capsulorrhexis was performed with a bent 25-gauge needle. Lens material was aspirated with an aspirating cannula (Anis; Storz, St Louis, MO, USA). In some eyes, posterior capsulotomy and anterior vitrectomy were performed with a vitrector instrument (Occutome; CooperVision, Irvine, CA, USA).

Paracenteses and IOL wounds were closed with interrupted 10-0 sutures (Mersilene; Ethicon, Edinburgh, Scotland, UK).

In group 1 (24 children, 34 eyes), the following modifications were made. A scleral groove was formed $2 \mathrm{~mm}$ from the limbus with a No. 64, Beaver blade. A scleral pocket was constructed with a crescent knife, and dissection was extended for $1 \mathrm{~mm}$ into the clear cornea. Using a 3.6-mm keratome (Visitec), the anterior chamber was entered through the scleral tunnel. In group 2 (22 children, 33 eyes), the cornea was entered at the 12-o' clock meridian just anterior to the terminal ends of the conjunctival blood vessels as they cross the limbus. A balance-type IOL (Hanita Lenses, Kibbutz Hanita, Israel) was implanted in the eyes of group 1, and a foldable IOL (AcrySof, Alcon, TX, USA) was used in group 2. In most cases, the IOL was implanted in the capsular bag, but in some cases, it was placed in the sulcus.

All operations were performed by the same surgeon (AS), using the same surgical technique modified as described for each group. All patients were treated postoperatively with dexamethasone sodium phosphate and neomycin sulphate eye drops applied 6 times a day for 1 week and then 4 times a day for an additional 2 weeks, and with $0.5 \%$ tropicamide twice a day for 2 weeks.

The refractive error of the surgically treated eye was measured (as part of a complete eye examination) with streak retinoscope 1 week after surgery and then, on average, every 1-2 months for 5 months after dilation of the pupil with $0.5 \%$ tropicamide. In all patients, the refractive error was corrected with spectacles 1 month after surgery, and treatment for amblyopia was instituted when indicated. No sutures were removed during follow-up.

The paired $t$-test was used to compare the magnitude of postoperative astigmatism at different postoperative periods. Spearman's correlation was used to determine the correlation between patient's age and postoperative refractive astigmatism, with patient's age as the nondependent variable. The dependent variables were as follows: postoperative refractive astigmatism assessed at 1 week, 3 months, and 5 months postoperatively, and the magnitude of astigmatism change between those examinations. $P$-values less than 0.05 were considered significant.

\section{Results}

A total of 46 children were included in this study. In 21 patients (10 patient's in group 1, and 11 patients in group 2) both eyes were operated on with the same technique. In these cases, only the first operated eye was included in the study.

The children were aged 2 months to 12 years. Mean \pm SD ages in groups 1 and 2 were $2.7 \pm 2.4$ and $4.5 \pm 3.2$ years, respectively. The children in group 2 were statistically significantly older than those in group 1 $(P=0.042)$. In each case, both the surgical and the postoperative courses were uneventful, and there were no complications.

Table 1 and Figures 1 and 2 present the mean values and ranges of astigmatism after surgery in the different groups. In all, 13 children out of 24 (54\%) and 12 children out of $22(55 \%)$ had 1-week postoperative astigmatism lower than $3 \mathrm{D}$ in groups 1 and 2, respectively. The

Table 1 Refractive astigmatism outcomes after congenital cataract surgery and intraocular lens implantation ${ }^{\text {a }}$

\begin{tabular}{lcc}
\hline & \multicolumn{2}{c}{ Type of surgery } \\
\cline { 2 - 3 } & $\begin{array}{c}\text { Scleral tunnel } \\
(\mathrm{n}=22)\end{array}$ & $\begin{array}{c}\text { Clear corneal incision } \\
(\mathrm{n}=24)\end{array}$ \\
\hline $\begin{array}{l}\text { Postoperative } \\
\text { astigmatism }(D)\end{array}$ & \\
At $1 \mathrm{wk}$ & $3.1 \pm 2.8(0-10)$ & $2.1 \pm 1.7(0-6)$ \\
At 3 mo & $1.3 \pm 1.4(0-5)$ & $0.9 \pm 0.9(0-3)$ \\
At 5 mo & $1.1 \pm 1.2(0-4)$ & $0.9 \pm 1.0(0-4)$ \\
& & \\
Postoperative & & $1.2 \pm 1.7$ \\
astigmatism change $(D)$ & $1.9 \pm 2.7$ & $0.02 \pm 1.1$ \\
1 wk-3 mo & $0.15 \pm 0.9$ & 0.007 \\
3 mo-5 mo & 0.002 & \\
P-value & & \\
\hline
\end{tabular}

$\mathrm{D}=$ diopters; $\mathrm{wk}=$ week; $\mathrm{mo}=$ months.

${ }^{a}$ Values are expressed as mean \pm SD (range). The $P$-values represent the statistical significance of the astigmatism change during the first 3 postoperative months as opposed to the following 2 months. 

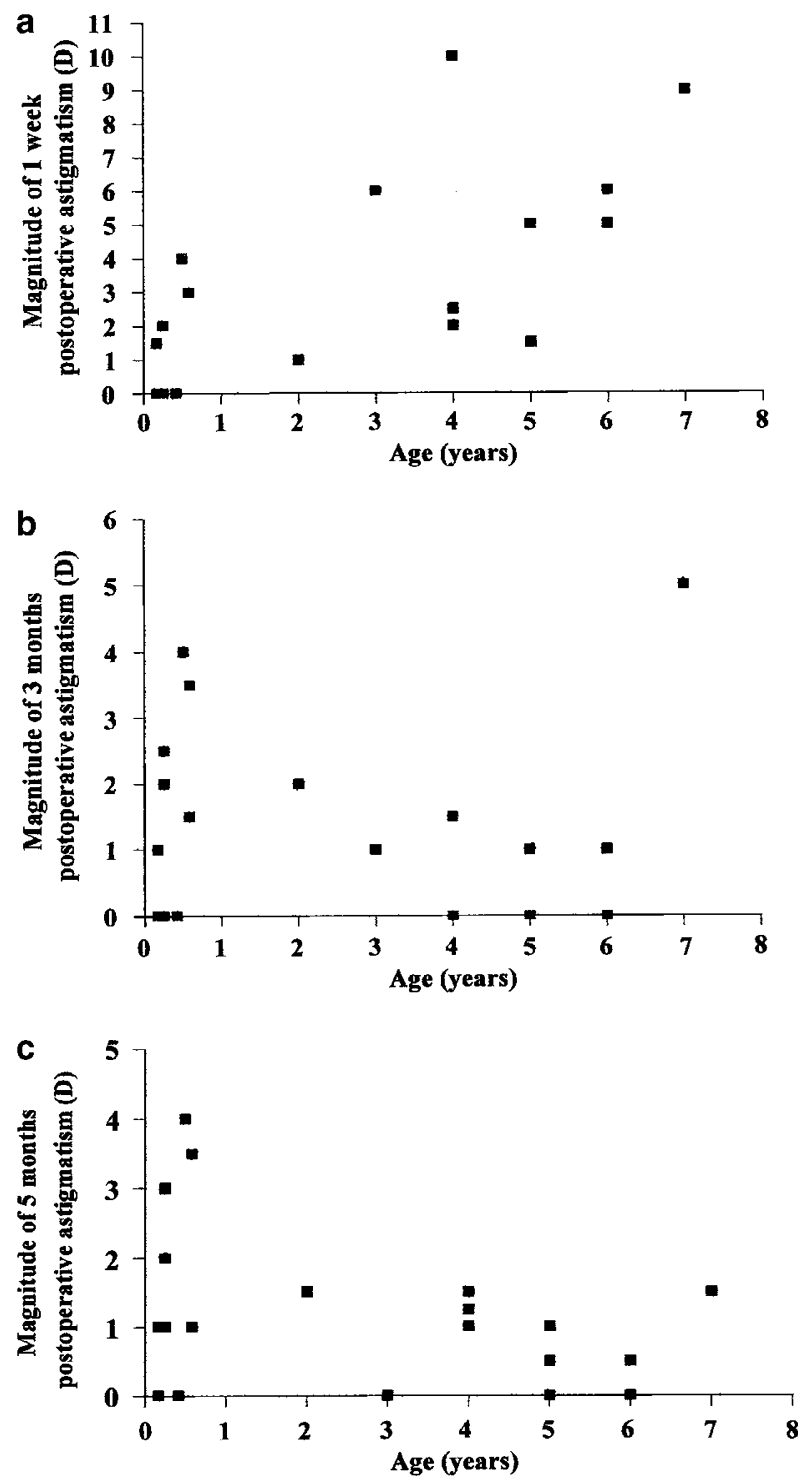

Figure 1 Correlation of patient's age to magnitudes of refractive astigmatism at 1 week (a), 3 months (b), and 5 months (c) after congenital cataract surgery using scleral tunnel incision.

children in both groups showed a decline in mean astigmatism with time. In both groups, the mean change in astigmatism was greater during the first three postoperative months than during the following 2 months (Table 1).

The observed changes in astigmatism between 1 week and 5 months after surgery were statistically significant in the two groups $(P<0.003$ in both groups).

Table 2 and Figures 1 and 2 present the correlation of patient's age to magnitude of postoperative refractive astigmatism. In group 1, patients' age was positively correlated with 1-week postoperative astigmatism
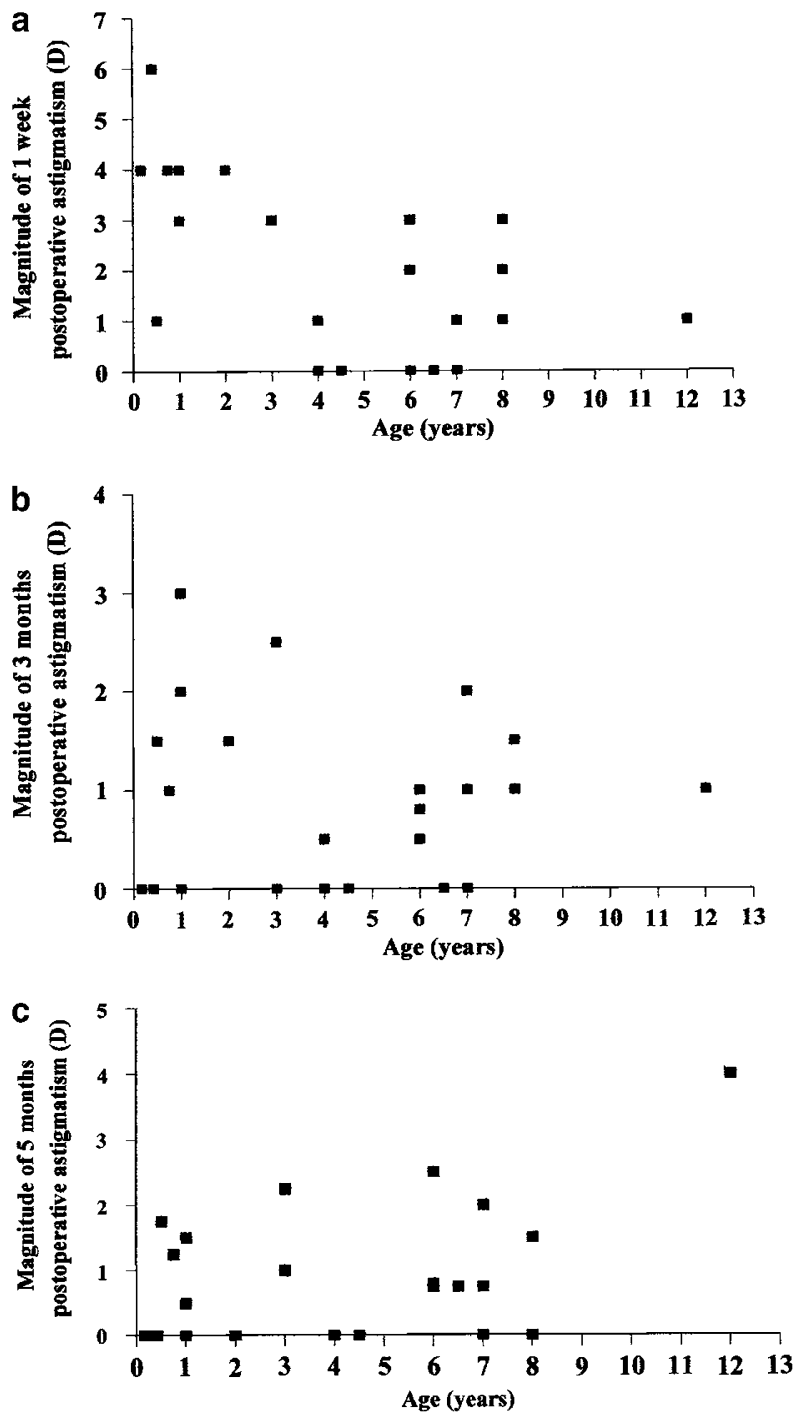

Figure 2 Correlation of patient's age to magnitudes of refractive astigmatism at 1 week (a), 3 months (b), and 5 months (c) after congenital cataract surgery using clear corneal incision.

( $r=0.64 ; P=0.001)$, and negatively correlated with the change in cylinder magnitude between 1 week and 3 months postoperatively $(r=-0.67 ; P=0.001)$. On the contrary, in group 2 patients' age was negatively correlated with 1-week postoperative astigmatism $(r=-0.58 ; P=0.003)$, and positively correlated with the change in cylinder magnitude between 1 week and 3 months postoperatively $(r=0.50 ; P=0.013)$.

\section{Discussion}

The immediate postoperative astigmatism and its subsequent changes are affected by factors such as the surgical technique, type of suture used, and experience of 
Table 2 Correlation of patient's age to magnitude of refractive astigmatism and its change during 5 month after congenital cataract surgery

\begin{tabular}{|c|c|c|c|c|}
\hline \multirow[t]{3}{*}{ Dependent variable } & \multicolumn{4}{|c|}{ Correlation with patient's age } \\
\hline & \multicolumn{2}{|c|}{ Scleral tunnel $(\mathrm{n}=22)$} & \multicolumn{2}{|c|}{ Clear corneal incision $(\mathrm{n}=24)$} \\
\hline & $\mathrm{r}$ value ${ }^{\mathrm{a}}$ & P-value ${ }^{\mathrm{b}}$ & $\mathrm{r}$ value $\mathrm{a}^{\mathrm{a}}$ & P-value \\
\hline \multicolumn{5}{|l|}{ Postoperative refractive astigmatism } \\
\hline At 1 week & 0.64 & $0.001^{*}$ & -0.58 & $0.003^{*}$ \\
\hline At 3 months & -0.05 & 0.82 & 0.08 & 0.72 \\
\hline At 5 months & -0.18 & 0.42 & 0.15 & 0.47 \\
\hline \multicolumn{5}{|l|}{ Change in magnitude of refractive astigmatism } \\
\hline Between 1 week and 3 months postoperatively & -0.67 & $0.001^{*}$ & 0.50 & $0.013^{*}$ \\
\hline Between 3 months and 5 months postoperatively & -0.30 & 0.17 & 0.09 & 0.68 \\
\hline
\end{tabular}

'The $r$ values represent Spearman's coefficient of the correlation between patients' age and the dependent variables.

'The $P$-values represent the statistical significance of the correlation between patients' age and the dependent variables.

${ }^{*}$ A significant correlation $(P<0.05)$.

the surgeon. ${ }^{1-3,13}$ Cataract surgery in children, with or without anterior vitrectomy, can be done through small limbal incisions. ${ }^{14}$ For IOL implantation, the incision must be enlarged in accordance with the diameter of the lens to be implanted. Postoperative astigmatism may be affected by the width of the incision constructed in the sclera and the need to suture this cut in children. The relatively small astigmatism reported after scleral tunnel in other studies may have been attributable to sutureless surgery. ${ }^{15-17}$

In the present study, postoperative stigmatism showed a spontaneous decrease during the period between 1 week and 5 months after surgery, with most of this decrease seen during the first 3 months. The decline in astigmatism occurred in all patients regardless of the mode of surgical incision. In patients who underwent cataract surgery, using scleral tunnel incision (group 1), the older the children's age, the higher the early postoperative astigmatism and its spontaneous regression during the first 3-month follow-up. In contrast, for patients who underwent cataract surgery, using clear corneal incision (group 2), the younger the child's age, the higher the early postoperative astigmatism and its spontaneous regression during the first 3-month follow-up.

The differences between young and old children, which were shown after operations with clear corneal incision, can be explained by the unique features of children's eyes, which are altered during development. The high elasticity of the sclera in young patients may explain both the high early-postoperative astigmatism and the astigmatism regression after cataract surgery. Highly elastic sclera in young children necessitates careful wounds closure to result in high earlypostoperative astigmatism. On the other hand, in young children, because of the elasticity of the cornea and sclera and the growth of the globe, the tissue tension can spread evenly to neighboring areas, reducing the amount of astigmatism over the follow-up period. More research is needed to validate and to explain the contradicted relationship between patient's age and postoperative astigmatism after congenital cataract surgeries using different incision techniques.

Previous studies have reported regression of absolute postoperative astigmatism after congenital cataract surgery. Brown et al ${ }^{12}$ reported spontaneous relaxation of postoperative astigmatism in children after lens implantation through a $6.25-\mathrm{mm}$ scleral wound. In that study, the mean astigmatism was $6.71 \mathrm{D}$ at $1-15$ days after surgery and $1.93 \mathrm{D}$ at $31-45$ days. The authors concluded that surgeons should not hesitate to secure scleral wounds meticulously in children because of fear of a permanent undesirable refractive outcome.

In our patients, the astigmatism decreased more rapidly, on average, during the first 3 months after the operation than during the following 2 months. This decline in astigmatism with time was observed in both groups, and there was no evidence of 'cheese-wiring' of the sutures through the sclera. Similar findings were reported in adults, ${ }^{7,18}$ in whom surgery-induced astigmatism declined rapidly during the first 1 or 2 months postoperatively. In another study, ${ }^{19}$ the corneal curvature stabilized at 19 weeks after surgery. On the basis of their own results, Talamo et $a l^{7}$ concluded that it may be unwise to cut the sutures in patients with early postoperative astigmatism of less than $3 \mathrm{D}$ because of the instability of the corneal astigmatism.

The finding of postoperative astigmatism is important, especially in children, because of its adverse effect on vision development and the risk of amblyopia. ${ }^{20}$ In 
adults, a few months of delay in correcting the refractive error does not affect the final visual acuity, whereas in children, the optical refraction must be precisely corrected as soon as possible. Accordingly, the refractive error in all of our patients was corrected 1 month after surgery, and any further changes in astigmatism were promptly attended to by changes in the refractive correction. On the other hand, whereas postoperative surgical astigmatism in adults can be corrected by removal of 1 or more sutures in a simple office procedure, ${ }^{6,7}$ in children this procedure usually requires general anesthaesia.

Adjusting the locations for IOL incision (superior vs temporal $v s$ oblique) according to preoperative keratometric readings may decrease postoperative astigmatism. Comparison of preoperative and postoperative keratometric results is needed in order to prove the efficacy of this method. Such information cannot be learned from the present study since postoperative keratometry was not measured and only superior incision was used for IOL implantations in this study population.

In conclusion, suture removal is recommended in adults as a way to correct postoperative astigmatism. The findings of the present study strongly suggest that removal of sutures in children is not required, because the astigmatism regresses spontaneously a few months after surgery. This would eliminate the need for the general anesthaesia that is usually necessary for suture removal in children. However, close monitoring and prompt correction of postoperative refraction error is needed especially in young patients after cataract operation, using clear corneal incision, and in older ones after operations, using scleral tunnel incisions.

\section{Acknowledgements}

This study was supported by a grant from the Sackler Faculty of Medicine, Tel-Aviv University, Tel-Aviv, Israel.

\section{References}

1 Jaffe NS. Postoperative corneal astigmatism. In: Jaffe NS. Cataract Surgery and its Complications, 3rd edn. CV Mosby Co: St Louis, MO, 1981; 92-110.

2 Seeto R, Ng S, McClellan KA, Billson FA. Nonabsorbable suture material in cataract surgery: a comparison of Novafil and nylon. Ophthalmic Surg 1992; 23: 538-544.
3 Gimbel HV, Sun R, DeBroff BM. Effects of wound architecture and suture technique on postoperative astigmatism. Ophthalmic Surg Lasers 1995; 26: 524-528.

4 Kronish JW, Forster RK. Control of corneal astigmatism following cataract extraction by selective suture cutting. Arch Ophthalmol 1987; 105: 1650-1655.

5 Richards SC, Brodstein RS, Richards WL, Olson RJ, Combe PH, Crowell KE. Long-term course of surgically induced astigmatism. J Cataract Refract Surg 1988; 14: 270-276.

6 Rowan FJ. Corneal astigmatism following cataract surgery. Ann Ophthalmol 1978; 10: 231-234.

7 Talamo JH, Stark WJ, Gottsch JD, Goodman DF, Pratzer K, Cravy TV et al. Natural history of corneal astigmatism after cataract surgery. J Cataract Refract Surg 1991; 17: 313-318.

8 Axt JC. Longitudinal study of postoperative astigmatism. J Cataract Refract Surg 1987; 13: 381-388.

9 Storr-Paulsen A, Vangsted P, Perriard A. Long-term natural and modified course of surgically induced astigmatism after extracapsular cataract extraction. Acta Ophthalmol (Copenhagen) 1994; 72: 617-621.

10 Stanford MR, Fenech T, Hunter PA. Timing of removal of sutures in control of post-operative astigmatism. Eye 1993; 7: 143-147.

11 Spierer A, Bar-Sela SM. Changes in astigmatism after congenital cataract surgery and foldable intraocular lens implantation. J Pediatr Ophthalmol Strabismus 2004; 41(1): 35-38.

12 Brown SM, Hodges MR, Corona J. Relaxation of postoperative astigmatism after lens implantation through a $6.25 \mathrm{~mm}$ scleral wound in children. J Cataract Refract Surg 2001; 27: 2012-2016.

13 O'Driscoll AM, Goble RR, Hallack GN, Andrew NC. A prospective, controlled study of a $9 / 0$ elastic polypropylene suture for cataract surgery: refractive results and complications. Eye 1994; 8: 538-542.

14 Wilson ME, Elliott L, Johnson B, Peterseim MM, Rah S, Werner $L$ et al. AcrySof acrylic intraocular lens implantation in children: clinical indications of biocompatibility. J AAPOS 2001; 5: 377-380.

15 Oshima Y, Tsujikawa K, Oh A, Harino S. Comparative study of intraocular lens implantation through $3.0 \mathrm{~mm}$ temporal clear corneal and superior scleral tunnel self-sealing incisions. J Cataract Refract Surg 1997; 23: 347-353.

16 Olsen T, Dam-Johansen M, Bek T, Hjortdal JO. Corneal vs scleral tunnel incision in cataract surgery: a randomized study. J Cataract Refract Surg 1997; 23: 337-341.

17 Gross RH, Miller KM. Corneal astigmatism after phacoemulsification and lens implantation through unsutured scleral and corneal tunnel incisions. Am J Ophthalmol 1996; 121: 57-64.

18 Floyd G. Changes in the corneal curvature following cataract extraction. Am J Ophthalmol 1951; 34: 1525-1533.

19 Jampel HD, Thompson JR, Baker CC, Stark WJ. A computerized analysis of astigmatism after cataract surgery. Ophthalmic Surg 1986; 17: 786-790.

20 Fulton AB, Dobson V, Salem D, Mar C, Petersen RA, Hansen RM. Cycloplegic refractions in infants and young children. Am J Ophthalmol 1980; 90: 239-247. 